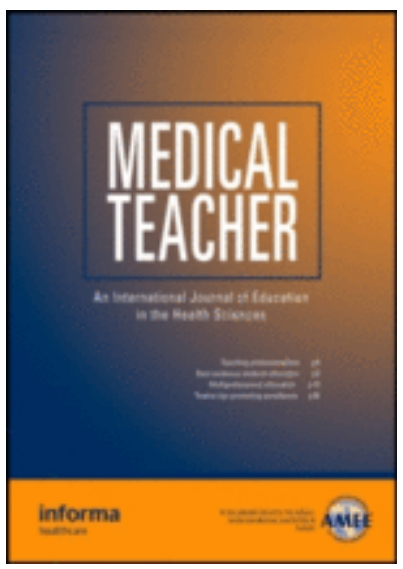

\title{
Exploring the Perceived Medical Ethics and Law Training Needs of UK Foundation Doctors
}

\begin{tabular}{|c|c|}
\hline Journal: & Medical Teacher \\
\hline Manuscript ID & CMTE-2019-0740.R1 \\
\hline Manuscript Categories: & Articles \\
\hline $\begin{array}{r}\text { Date Submitted by the } \\
\text { Author: }\end{array}$ & $\mathrm{n} / \mathrm{a}$ \\
\hline Complete List of Authors: & $\begin{array}{l}\text { Machin, Laura; Lancaster University, Lancaster Medical School } \\
\text { Latcham, Natalie; Morecambe Bay Hospitals NHS Trust } \\
\text { Lavelle, Claire; Wirral Community NHS Foundation Trust, GP Speciality } \\
\text { Training } \\
\text { Williams, Richard; Lancaster University, Management School } \\
\text { Corfield, Lorraine; University Hospitals of North Midlands NHS Trust; } \\
\text { Keele University, Medical School }\end{array}$ \\
\hline Keywords: & $\begin{array}{l}\text { Ethics/attitudes }<\text { Learning outcomes, Curriculum, Postgraduate }<\text { Phase } \\
\text { of education, Teaching \& Learning, Medicine }<\text { Profession }\end{array}$ \\
\hline
\end{tabular}

\section{SCHOLARONE \\ Manuscripts}




\section{TITLE PAGE}

Manuscript title: Exploring the Perceived Medical Ethics and Law Training Needs of UK Foundation Doctors

Short title: MEL Training Needs for Foundation Doctors

Authors: Machin, L.L. ${ }^{1}$, Latcham, $\mathrm{N}^{2}$, Lavelle, $\mathrm{C}^{3}$., Williams, R.A ${ }^{1}$, and Corfield, $\mathrm{L}^{4,5}$

Institutions: ${ }^{1}$ Lancaster University; ${ }^{2}$ University Hospitals of Morecambe Bay Foundation Trust ${ }^{3}$ Wirral GP Specialty Training Scheme; ${ }^{4}$ Keele University; ${ }^{5}$ University Hospital of North Midlands NHS Trust

Corresponding author: Dr Laura Machin, Lancaster Medical School, Faculty of Health and Medicine, Lancaster University, Lancaster, LA1 4YW, 01524 65201, l.machin@lancaster.ac.uk 


\section{Exploring the Perceived Medical Ethics and Law Training Needs of UK Foundation Doctors}

\section{Introduction}

Foundation Doctors (FDs) have trouble dealing with medical ethics and law (MEL) issues they encounter in practice (O’Neill et al. 2003; Shibu et al. 2008; Matheson C and Matheson D 2009; Illing et al. 2013; Vivekananda-Schmidt and Vernon 2014). The dearth of empirical research that focuses on the ethical issues FDs encounter in practice, complicates this picture (McDougall and Sokol 2008). FDs have difficulties speaking up and taking concerns to senior colleagues, they can lack support from senior colleagues (Paice et al. 2002; Goldacre et al. 2003), and can experience conflicting values when faced with working on the frontline (Benson 2014). The first few postgraduate years are known to be physically and emotionally demanding (Rogers et al. 2014). Providing support during these early years is not only critical for job satisfaction and the wellbeing of FDs, but also for patient satisfaction and quality of patient care (ibid.).

Concerns have been raised surrounding the lack of training FDs receive on MEL issues, and there have been calls to ensure that the formal teaching provided encompasses MEL topics (Levy and Coward 2010). At present, the training FDs receive has a significant emphasis on clinical competencies (Linklater 2010) and limited content on MEL topics (Levy and Coward 2010; Benson 2014).

The lack of support and reflective opportunities for FDs when facing MEL issues either from senior role models to serve as moral and practical guides (McDougall and Sokol 2008) or training and educational spaces has arguably led to a form of educational neglect (Linklater 2010). In this paper, we provide insight into the MEL challenges that FDs face, what they would like to receive training on during their first two years of work and how they would wish for that training to be delivered. We use the key topics that emerge from our findings to cautiously propose a minimum MEL curriculum for FDs, accepting that there may be practical challenges in delivering such a curriculum.

\section{The UK Foundation Programme}

A FD is a medical practitioner in the United Kingdom (UK) in the first 2 years following qualification. The Foundation Programme is designed to give FDs a range of general experience before choosing a speciality (Collins 2010). A curriculum for the Foundation Programme, developed in 2005 and updated over the years (Kirkham and Baker 2012), has been criticised for its "inherently vague" outcomes and 
measures of training quality (Dean and Duggleby 2013). The current syllabus (2016) for FDs is divided into four sections, of which one focuses predominately on professionalism, including some ethical and legal matters. Studies on the Foundation Programme have raised questions around the effectiveness and quality of the training (Collins 2010; Chauduri et al. 2013). FDs tend to rotate jobs or placements every few months, thereby limiting their ability to fully integrate into a team. The lack of stability can have a negative impact of FDs' ability to learn (Wakeling et al. 2011; Dean and Duggleby 2013) but equally can be an opportunity for extensive learning, if managed well.

\section{A need to focus on Foundation Doctors}

Research highlights that the multiple roles that FDs play predisposes them to a unique set of MEL issues (Chamsi-Pasha et al. 2016). FDs are a special group, negotiating the difficult transition from student to professional (Kirkham and Baker 2012) and are both clinician and learner (McDougall and Sokol 2008). Although both roles are not incompatible, an inherent tension is deemed to exist between them (Schaufeli et al. 2009). FDs experience MEL issues differently to medical students and more experienced junior doctors, given their position in the organisation and medical hierarchy (McDougall 2008), and the frequent rotations within the Foundation Programme. These rotations mean FDs experience a range of MEL issues, some unique to a particular medical speciality. Unlike senior doctors, who remain on the same clinical speciality and therefore gain experience of, and anticipate, MEL issues, FDs spend two years bombarded with a range of MEL issues as they rotate through their various placements. Yet, so far, there has been a dearth of MEL resources available dedicated to meeting FDs' needs. Instead, MEL resources have tended to address the medical profession as a whole or combine FDs with that of medical students (McDougall 2008; Chamsi-Pasha et al. 2016).

\section{A need for medical ethics and law training beyond medical school}

MEL issues arise far more frequently than most FDs anticipated when they attended medical school (Chamsi-Pasha et al. 2016). Both undergraduate and postgraduate educators have recognised the difference between discussing MEL issues at medical school to experiencing them as a FD, claiming that no amount of undergraduate teaching could fully prepare FDs for clinical practice when a decision is their responsibility with real world implications (Sokol et al. 2010; Vivekananda-Schmidt \& Vernon 2014;). Finally, experienced senior doctors may no longer perceive a situation as generating MEL matters, and therefore underappreciate the FD's need to be supported with and trained in MEL issues whilst on the rotation. 


\section{Contemplating medical ethics and law training for Foundation Doctors}

It is apparent from the literature that there are some areas of medicine that FDs feel more prepared to tackle than others (Benson 2014), with some areas deemed particularly troubling (Table 1). There have been calls for educators to focus on the day-to-day moral struggles faced by early career physicians (Braunack-Mayer 2001), and for progression from learning during medical school, using a practical emphasis and focus (Sokol 2010). Yet, significant work still needs to be conducted to develop FD curricular content recommendations (Roberts et al. 2005), including the design and delivery.

Exploring how Foundation training can be improved has been infrequently considered (for a notable exception see Blencowe 2015). When the development of FDs is considered, a retrospective approach is typically applied, focusing upon (revising) medical school curricula (Wall et al. 2006). Rarely are FDs asked what they perceive they need at that point in their development, resulting in training that lacks relevance, meaning and usefulness for the learners (Roberts et al. 2005).

Ethics curricula have often been 'top down', structured in relation to abstract bioethical principles, rather than by FDs' experiences and self-identified educational needs, representing a more 'bottom up' approach (Hundert et al. 1996). This is particularly significant when considering the experiences of junior doctors do not remain constant through the ages (Sokol et al. 2010). Consequently, previously identified MEL challenges may only hold relevance for a specific period of time, or within a particular local culture, or medical speciality. What emerges then is the importance of paying attention to the everyday issues of medical ethics (Quarini 2010). Based on an extensive literature review of existing research, McDougall and Sokol (2008) call for undergraduate medical ethics curricula to give priority to the real life issues that students will encounter in their first years of practice.

Parallels can be drawn between the challenges facing those training medical students with FDs in three ways. Little time is given over to MEL within Foundation training (Kirkham and Baker 2012). Educators have responded with overviews of the 'essential' MEL issues for junior doctors (see Table 2), which is complicated by FDs different needs for ethics preparation as a result of their different specialities during their two years of training (Diekema and Shugerman 1997). Furthermore, questions have been raised over the purpose of MEL training for FDs, with prominent voices claiming it is "not to provide junior doctors with a solution to their problems, but to whet their ethical curiosity and provide them with a deeper appreciation of the pervasiveness of medical ethics" (Sokol 2010). Others argue it should help inculcate the clinical and ethical decision-making skills and professional values needed to be a good doctor (Robins et al. 2002). 
In terms of delivering any MEL training for FDs, a range of methods are advocated including individual clinical supervision and mentoring, consultation with experts, didactic and small group learning (Roberts et al. 2005). Educators are warned against exclusively relying on lectures, despite the perceived ease of their delivery and preparation (Kirkham and Baker 2012). Learning in facilitated small groups remains the 'gold standard' (ibid.) as it helps to promote peer support, and allows junior doctors to explore ways of dealing with difficult situations in a safe environment (Linklater 2010). The training should be oriented to authentic ethical dilemmas experienced by the junior doctor (Linklater 2010; Chamsi-Pasha et al. 2016) as learning is context dependent and the influence of role modelling in these situations cannot be overemphasised (Linklater 2010).

\section{Methods}

The aims of the study were to identify the MEL training needs of FDs in the UK by using an on-line survey answered by FDs in both their first and second Foundation year. We aimed to understand what FDs need to support them in their current role, whilst also appreciating that their perceptions of current needs is likely to be influenced by their previous training. We therefore have also asked about medical school training on MEL. Demographic data was collected regarding respondents' gender, age, year of training, and medical school attended, the Deanery of their Foundation training, and whether respondents had completed a Masters in MEL. The main body of the survey focused on the respondents' MEL training as a medical student and as a FD, and the MEL training respondents would like to receive as FD.

The content of the survey was informed through multiple published sources including the British Medical Association Medical Ethics Today Handbook, the Institute of Medical Ethics core curriculum, the General Medical Council Generic Professional Capabilities, and issues identified in previous studies on FDs' MEL needs. We also engaged with and gathered feedback from key stakeholders from British Medical Association, General Medical Council, Health Education England, and UK Foundation Directors Committee. The survey was tested by two members of the research team, who were FDs at the time of testing.

We anticipated that FDs would be time pressured and that FDs were likely to complete the survey on their mobile phone. We reflected this in the design of the survey by using question and answer formats that were easily accessed on mobile phones, such as multiple choice, tick boxes and slide scales. We limited the amount of open questions requiring significant text to be typed.

Ethical approval was obtained from the research ethics committee of the Faculty of Health and Medicine at Lancaster University and from Health Education England. The survey was promoted with support from the UK Foundation Programme and the 
Institute of Medical Ethics. Participation in the survey was voluntary and no incentives were offered to encourage participation. The on-line survey provider, SurveyMonkey, was used to gather the data over a six-week period. Recruitment took place between February and March 2018 to ensure FDs had gained at least six months of experience in their new role (Byrne et al. 2016).

Both quantitative and qualitative data were collected and analysed. Qualitative data were read and coded according to the theme/s within each response. Themes consisted of generic, high level themes, such as 'end of life care' and 'emergency decisionmaking', and narrower, specific themes such as 'FD role', 'confidence', 'prepared for practice'. We also considered how frequent a theme emerged within the qualitative data, and whether a theme was more often discussed according to respondents' demographics.

As with other studies involving FDs (Van Hamel and Jenner 2015), the main limitation of our study relates to the generalisability of the findings. Approximately $3 \%$ of all UK FDs completed the survey; a similar response rate to that of other studies involving FDs (Dean and Duggleby 2013; Tasker et al. 2014). As noted from previous researchers (Wall et al. 2006), junior doctors are a notoriously difficult group to encourage to complete questionnaires. A concern of low response rates in surveys is response bias because it is considered that respondents differ in their views compared to non-respondents (Armstrong and Ashworth 2000; Matheson C and Matheson D 2009; Dean and Duggleby, 2013; Tasker et al. 2014). However, the present study does provide a snapshot of opinions from hundreds of FDs.

The main strength of our survey arises from the recruitment of FDs in their first and second years of training, which differs from existing studies that have typically focused on medical students and FDs in their first year of training, with outcomes focusing upon undergraduate curricula. We have asked current FDs about the MEL issues they face and what training has been of benefit and is needed to meet the MEL challenges. Our findings then hold relevance to both undergraduate and postgraduate educators. The inclusion of FDs in their first and second years of training also means we avoid concerns raised in previous studies that any perceptions of FDs in their first year of training might just be a reflection of them starting a new job (Van Hamel and Jenner 2015). Finally, we have also gathered qualitative data, which provides a deeper exploration of the issues identified in the quantitative analysis, but can be difficult to gather from junior doctors through on-line surveys (Linklater 2010).

\section{Results}

In total, 479 respondents completed the survey. Table 3 outlines the demographic profiles of all respondents. The majority of respondents were female $(64.3 \%)$, aged between 25 and 29 years of age (60.96\%), had attended a medical school in England 
(66.81\%), and were currently located in a Foundation School in England (69.11\%). Approximately $45 \%$ of respondents were in their first year of Foundation training, and approximately $53 \%$ were in their second year.

\section{MEL training at medical school}

All respondents were asked what MEL training they had received whilst at medical school. Table 4 outlines topics that over three quarters of respondents who answered the question had received MEL training on at medical school. Nearly all respondents $(>90 \%)$ who answered the question had received MEL training on confidentiality (95.53\%), and consent and assessing capacity (90.38\%). Table 5 outlines topics that less than half of all respondents who answered the question had received training on at medical school. Less than a quarter of all respondents who answered the question had received MEL training on the structure of the legal system (23.94\%), and sedating patients $(22.37 \%)$.

All respondents were asked what topics they would have wished to have received MEL training on at medical school (see Table 6). Over $10 \%$ of all respondents who answered the question stated they would have wanted to receive MEL training on self-discharge against medical advice (17.54\%), structure of the legal system (15.78\%), and deprivation of liberty safeguards (15.08\%).

The qualitative data highlighted the desire from respondents for the practical application of MEL training whilst at medical school, "more practical applications of MEL principles e.g. situations relevant to junior doctors on the ward...", "practicalities of common ethical scenarios on the ward", "confidentiality in a practical setting - what to say/not say when family/friends phone or visit the ward", "I think more in depth discussions regarding DNACPR [Do Not Attempt Cardiopulmonary Resuscitation] and ceilings of care would have been useful. Although we were taught it in medical school I still did not feel fully prepared to engage in discussions around such matters".

Respondents expressed a wish for time available for case based discussion within MEL training at medical school, using real-life cases, and support to guide them through the MEL issues within the cases, "what I would have really liked is to have had the opportunity to actually discuss these areas of the curriculum", "real life situations collected from other FY [Foundation Years'] experiences", "often the lectures were not practical enough in the sense that we have to put the theory into application within practice", and "more structured scenario teaching on cases".

\section{MEL training during the Foundation Programme}

All respondents were asked what training they would like to receive during their Foundation years (Table 7). Approximately two thirds of those who answered this 
question stated they would wish to receive MEL training as a FD on self-discharge against medical advice $(70.7 \%)$, sedating patients $(70.0 \%)$, decision making in emergency medicine $(67.0 \%)$, and withholding and withdrawing treatment $(66.0 \%)$. All respondents were asked what they had received training on at medical school. A relatively low percentage of respondents who answered this question had received undergraduate training on self-discharge against medical advice (30.48\%) and sedating patients $(45.71 \%)$, whilst the majority reported receiving teaching on decision making in emergency medicine $(88.57 \%)$ whilst at medical school.

Over half of all respondents want MEL training during their Foundation Programme on DNACPR orders $(63.5 \%)$, dealing with patients with suicidal intent $(58.8 \%)$, the Mental Health Act (55.3\%), Deprivation of Liberty Safeguards (53.9\%), and end of life care $(53.2 \%)$. Respondents who answered what training they had received at medical school stated DNACPR (74.2\%), the Mental Health Act (82.86\%), and end of life care $(77.14 \%)$.

Table 7 shows the self-perceived training needs of respondents according to their year of Foundation training i.e. 1 or 2. A minimal difference between the Foundation Year groups was found for four topics. There was a notable difference between FY1 and FY2 when considering the structure of the legal system, with $36.2 \%$ of FY2 doctors wanting training on this compared to $61.3 \%$ of FY1 doctors.

Within the qualitative data, respondents asked for training as a FD relating to paperwork on DNACPR - "Who can fill out a DNACPR for it be valid?" (Female, FY1) - and DOLs [Deprivation of Liberty Safeguards] - "It would be useful to have practical teaching for example how to actually complete a DOLs form" (Female, FY2). Respondents also identified further training required during their Foundation Programme that discussed "end of life in emergency situation out of hours" (Female, FY1), and promoted "Better understanding of when and how to section a patient in a hospital (non psych environment) +/-use the doctor's holding power" (Male, FY2).

All respondents were asked how they would wish to receive any additional training on MEL issues during their Foundation Programme (see Table 8). Over half of respondents expressed their preference for case studies (64.55\%), seminars (58.69\%), and workshops (51.17\%). The FDs also proposed e-learning, debate forums with MEL experts, and departmental training and debriefing relating to 'difficult' cases as other alternative modes of learning MEL during their Foundation training.

\section{MEL issues faced by FDs}

Respondents were asked what they had observed or experienced that had been ethically and/or legally challenging during their Foundation training. Two hundred and thirty-seven respondents provided a qualitative response to this question. The MEL challenges for FDs have been summarised thematically below. 


\section{End of Life Care and DNACPR}

A common theme to arise from this question was multiple ethical dilemmas surrounding end of life care, with 55 respondents referring to it in their comments. DNACPR decisions and withdrawing treatment were most often mentioned by respondents, who described a lack of support available to them and feeling left to make these difficult decisions. Fifty-one respondents explicitly referred to completing the paperwork related to end of life care, such as DNACPR forms, as challenging as well as communicating these decisions with patients and next of kin, as one respondent described, "End of life conversations - DNACPR decisions (although these are always reviewed by somebody senior - it's the initial conversation which is often my role as an FY)" (Male, FY2). Respondents reported MEL issues were exacerbated by the timing of when they took place, such as out of hours as one respondent explained, "Feeling that I would like a DNACPR to be put into place for a patient but not knowing how to do that or having senior around to facilitate it being put in place" (Female, FY1).

Conflict was typically at the heart of respondents' comments about end of life issues, either between family members - "End of life decisions involving conflicted views of family members" (Female, FY1) - or between the family and the clinical team "DNACPR decisions when family/patient do not wish to have DNACPR" (Female, FY2). Patient confidentiality was also frequently referred to by respondents as challenging when caring for patients at the end of their lives, particularly when attempting to maintain confidentiality as the following quotes illustrate, "[a patient] never wanted anyone to know he had HIV, especially his family, however he died of AIDS after a lengthy stay in ITU. Difficult to keep family up to date while observing his wishes and not telling them about his HIV/AIDS status" (Male, FY2), and "Giving information to family about unwell/dying relative - how much is too much? What if they can't consent? What if we get a phone call from 'daughter' asking if parent more unwell and should she come in. How can we be sure the person over phone says who they say they are? Is checking address \& names enough?” (Female, FY2).

\section{Patient refusal}

Drawing on the qualitative data provided in the open text boxes, 45 respondents frequently presented patient refusal as ethically and/or legally challenging as a FD. Of these, 35 respondent specifically gave patients wishing to discharge against medical advice as an ethically difficult situation they had encountered during their Foundation Year(s). Respondents described a variety of other complex circumstances such as patients from GPs refusing to attend hospital when advised, patients with learning difficulties refusing treatments or intervention such as venepuncture, patients declining life-saving treatments, and patients under the age of 18 whom wished to decline treatment. The difficulty of assessing a patient wishing to discharge against medical advice (self-discharge) was particularly challenging when the FD was on-call because "you are not familiar with patient's medical situation" (Female, FY1). 
The dilemmas were exacerbated when the capacity of the patient was in question. Respondents referred to patients who were intoxicated, or potentially suicidal, and wanted to discharge themselves against medical advice. Attempting to assess a patient's capacity in these instances was considered ethically and/or legally challenging for respondents, as the following comment shows, "Assessing capacity to self discharge and being doubtful. Being exposed to this with knowledge of only the theory of dealing with this situation, but no practical experience was very difficult" (Female, FY2). In their comments, respondents queried whether it was appropriate for a FD in the first year of training to make decisions when facing patient refusal, as the following extracts illustrate, "Attempting to assess capacity in fraught situations and not feeling I have the skills to do so in this setting" (Female, FY1), and "Whilst we are not allowed to discharge patients we are allow[ed] to witness signing of a self-discharge, but it can be challenging assessing capacity" (Male, FY1).

\section{Sedation}

Drawing on the qualitative data provided in the open text boxes, 23 respondents reported encountering issues regarding sedation. One respondent commented, "Most of all I wish I was better prepared for the patient kicking off in the middle of the night when there are no seniors around. Do I sedate? How do I sedate? Do I call security? Do I stop them leaving? How do I practically and legally do that?" (Male, FY1).

\section{Deprivation of Liberty Safeguards (DOLS)}

Drawing on the qualitative data provided in the open text boxes, DOLS were referred to by 22 respondents who reported feeling they had insufficient training of how to complete the paperwork relating to DOLs, as the following extract illustrates, "Asked to put DOLs in place and do mental capacity assessments when you have had no formal training on Trust procedures, and people often want it doing quickly" (Female, FY2). Again, the challenging nature experienced by FDs surrounding DOLs was exacerbated by a lack of support available, as one respondent described, "Attempting to assess capacity in fraught situations and not feeling I have the skills to do so in this setting. Being the person who is approached to put a DOLs in place on weekend on call shift despite knowing nothing about the process when seniors are not imminently available to help" (Female, FY1).

\section{Whistleblowing}

In the qualitative data, there was a theme of respondents feeling unsure of how to whistleblow or seek advice on issues regarding senior or underperforming colleagues. One respondent wrote, "Most issues I have had are regarding working with colleagues and having different standards for how jobs should be done. Raising concerns about professional behaviour and poor clinical care is difficult, whether through discussion with the individual themselves or with a senior" (Female, FY2). Another recounted a difficult situation in which "I have had an episode of whistleblowing this year in FY2 
where I had to voice my concerns and it was quite stressful for me as this person was my senior colleague" (FY2). One FY1 stated "I have seen a lot of senior members act in ways I feel is ethically incorrect however the nature of the medical system is that senior members are never questioned or challenged and if they are this usually backfires on the person questioning leading to them being penalised. This causes a fear of standing up for patients' ethical rights in fear or bullying in the workplace, gaining a negative reputation and fear of dismissal. The problem lies with the senior staff abusing their power rather which leads to junior staff feeling limited in what they can achieve in terms of ethical and human rights" (Female, FY1).

\section{Discussion}

Through our survey, we provide insight into the topics troubling the FY respondents, and on which they wish to receive MEL training on in order to help them within their current role. As others have stated (Roberts et al. 2005), gathering the perspectives of learners cannot and should not be the sole guide to curricular content, nevertheless it is clear that for teaching to be effective, it must be meaningful - relevant, salient, useful and connected to the experiences of learners. Although, a relatively small percentage of FY doctors completed the survey, the demographics of the respondents are distributed well between gender and year of training, which supports the wider relevance of the results to FY training in general. For these reasons, we suggest that our findings provide the groundwork for a minimum MEL curriculum for Foundation Training to be proposed, which would sit alongside the current Foundation Year syllabus. We propose any minimum MEL curriculum should be delivered using case studies, and methods that facilitate and promote discussion, such as seminars and workshops. Based on our survey results the proposed minimum MEL curriculum for FDs should give serious consideration to including the following topics: selfdischarge against medical advice, sedating patients, decision making in emergency medicine, withholding / withdrawing treatment, DNACPR decisions, treating patients with suicidal intent, whistleblowing, the Mental Health Act, DOLs (now liberty protection safeguards), and end of life care as well as cases generated by the FDs themselves.

We make the argument for a MEL minimum curriculum within Foundation training as it highlights and acknowledges the unique position and needs of FDs specifically. Furthermore, it aligns the importance of training FDs on MEL issues with that of teaching medical students and addresses the possibility of inadequate and variable undergraduate teaching on MEL (Chamsi-Pasha et al. 2016).

Our findings hold relevance for medical schools and undergraduate educators. Our proposed minimum MEL curriculum for FDs could contribute to informing what is taught at medical school such as determining the balance between the focus on the 'controversial' (genetic testing and cloning) and the 'everyday' (breaching confidentiality, obtaining consent) (Chamsi-Pasha et al. 2016). Our results highlight 
the everyday relevance of learning MEL and therefore justifies to both students and colleagues why we need to teach MEL at medical schools at a time when time and resources for MEL activities within 'packed' curricula are increasingly under stress.

Our findings show that FDs would prefer more creative modes of learning MEL whilst at medical school. This presents challenges for undergraduate educators - not least because of resource limitations and, in the UK, the rapid increase in medical student numbers. Our respondents stated they wanted applied, practical and in some cases, advanced and in depth training on MEL whilst at medical school, in order to be prepared as a FD. Yet, MEL training at medical school needs to provide the building blocks for career-long practice of MEL. Even if a student receives extensive and applied ethics learning at medical school, further training will be appropriate at FD level. Our survey findings support the wish from FDs that they are taught specific MEL topics as FDs rather than at medical school. For example, $22.37 \%$ of respondents were taught about sedation as a MEL topic at medical school, only $8.42 \%$ stated they would have liked training on this at medical school, yet $70 \%$ want training on this at FD level.

We recognise that a number of challenges exist when contemplating a minimum MEL curriculum for FDs. Firstly, FDs will encounter different kinds of MEL dilemmas as their two years of Foundation training will involve different specialities and therefore they may experience different MEL needs, although this is something that undergraduate educators also face when students have a variety of patient experiences whilst on placement and rotations. Secondly, postgraduate educators will also need to determine the baseline of MEL knowledge as FDs move from their undergraduate home to Foundation School sites, and therefore need to give time during sessions to understand FDs existing knowledge around a topic. Thirdly, our findings are based on FDs across the UK and therefore our proposed minimum MEL curriculum presents a national picture, and 'local' FDs' MEL learning needs may differ. Fourthly, as with medical students, some FDs might lack ethical sensitivity and awareness, and therefore some FDs may not recognise the need for MEL training at this stage of their training. Finally, as with medical schools, implementing our proposed minimum MEL curriculum may be hindered by financial, resource, and time requirements within Foundation Schools.

\section{Conclusion}

We need to view Foundation training in MEL issues as practical ethics and law, and the training to be provided in a way that moves beyond the delivery modes in undergraduate education. Moreover, we need to view training on MEL issues as building upon the knowledge acquired at medical school, so it is the application of ethical and legal theories, principles, and concepts. 
We all need to accept that undergraduate MEL curricula cannot fully prepare our medical students for all the MEL challenges they will go on to face as a FD and beyond. It is important that MEL training is timely, appropriate and fitting. As reflected in the variation of feelings of preparedness between graduates of different medical schools (Brennan et al. 2010; Goldacre et al. 2010), MEL training should not be viewed as a one-off event and instead needs to be revisited and built upon. Therefore undergraduate and postgraduate MEL training need to be viewed in partnership, with postgraduate MEL training an extension of the learning the FD acquired during medical school.

When we consider the MEL challenges that our FDs are facing as identified in our findings, we are in danger of leaving ourselves open to accusations of 'educational neglect' (Linklater 2010). We accept that 'education' can seem a big word that conjures up classrooms, and delivered content, which equals time away from the ward, but it can also be far simpler, smaller, and subtler than that. MEL education can be incorporated into discussions within existing structures, such as multidisciplinary team meetings, and patient handovers. Ultimately, FDs work within and from teams therefore we should look to train them in this way. FDs learn clinically from and within a team, and their clinical training is a departmental concern - the same applies to FDs' MEL learning.

\section{References}

Armstrong D, Ashworth M. 2000. When questionnaire response rates do matter: a survey of general practitioners and their views of NHS changes. Br Journal Gen Practice. 50(455): 479-480.

Benson MR. 2014. How prepared do foundation doctors perceive themselves to be to face medical ethical dilemmas encountered in practice? [BSc thesis] UK: University of Leicester.

Blencowe NS, Van Hamel C, Bethune R, Aspinall R. 2015. 'From scared to prepared': targeted structured induction training during the transition from medical school to foundation doctor. Perspect on Med Education. 4: 90-92.

Braunack-Mayer AJ. 2001. What makes a problem an ethical problem? An empirical perspective on the nature of ethical problems in general practice. Journal of Med Ethics. 27: 98-103.

Brennan N, Corrigan O, Allard J, Archer J, Barnes R, Bleakley A, Collett T, De Bere SR. 2010. The transition from medical student to junior doctor: today's experiences of Tomorrow's Doctors. Med Education. 44: 449-458. 
Byrne D, Buttrey S, Carberry C, Lydon S, O’Connor P. 2016. Is there a risk profile for the vulnerable junior doctor? Ir Journal of Med Science. 185: 603-609.

Chamsi-Pasha H, Chamsi-Pasha M, Albar MA. 2016. Pragmatic message to junior doctors. Postgrad Med Journal. 92: 418-420.

Chaudhuri E, Mason NC, Newbery N, Goddard AF. 2013. Career choices of junior doctors: is the physician an endangered species? Clinical Medicine. 13: 330-335.

Collins J. 2010. Foundation for excellence: an evaluation of the foundation programme. London: Medical Education England.

Dean BJ. Duggleby PM. 2013. Foundation doctors' experience of their training: a questionnaire study. Journal of the R Society of Medicine Short Reports. 4: 1-7.

Diekema DS, Shugerman RP. 1997. An ethics curriculum for the pediatric residency program: confronting barriers to implementation. Archives of Pediatrics and Adolescent Medicine. 151: 609-614.

Goldacre MJ, Evans J, Lambert TW. 2003. Media criticism of doctors: review of UK junior doctors' concerns raised in surveys. Br Med Journal. 326: 629-630.

Goldacre MJ, Taylor K. Lambert TW. 2010. Views on junior doctors about whether their medical school prepared them well for work: questionnaire surveys. BMC Med Education. 10: 78.

Gore DM. 2001. Ethical, professional, and legal obligations in clinical practice: a series of discussion topics for postgraduate medical education Topic 4: confidentiality. Postgrad Med Journal. 77: 443-444.

Hundert EM, Douglas-Steele D, Bickel J. 1996. Context in medical education: the informal ethics curriculum. Med Education. 30: 353-364.

Illing JC, Morrow GM, nee Kergon CRR, Burford BC, Baldauf BK, Davies CL, Peile EB, Spencer JA, Johnson N, Allen M, et al. 2013. Perceptions of UK medical graduates' preparedness for practice: a multi-centre qualitative study reflecting the importance of learning on the job. BMC Med Education. 13: 34.

Kirkham D, Baker P. 2012. Twelve tips for running teaching programmes for newly qualified doctors. Med Teach. 34: 625-630. 
Levy J, Coward B. 2010. Ethical dilemmas: a focus of discussion for junior doctors. Postgrad Med Journal. 86: 631-631.

Linklater GT. 2010. Educational needs of foundation doctors caring for dying patients. Journal of R Coll Physicians Edinb. 40: 13-8.

McDougall R. 2008. The junior doctor as ethically unique. Journal of Med Ethics. 34: 268-270.

McDougall R, Sokol DK. 2008. The ethical junior: a typology of ethical problems faced by house officers. Journal of the R Society of Medicine. 101: 67-70.

Matheson C, Matheson D. 2009. How well prepared are medical students for their first year as doctors? the views of consultants and specialist registrars in two teaching hospitals. Postgrad Med Journal. 85: 582-589.

O'Neill PA, Jones A, Willis SC, McArdle PJ. 2003. Does a new undergraduate curriculum based on Tomorrow's Doctors prepare house officers better for their first post? a qualitative study of the views of pre-registration house officers using critical incidents. Med Education. 37: 1100-1108.

Paice E, Heard S, Moss F. 2002. How important are role models in making good doctors? Br Med Journal. 325: 707.

Quarini CJ. 2010. A day in the life of a junior doctor: everyday ethical encounters. Postgrad Med Journal. 86: 632 - 635.

Roberts LW, Warner TD, Hammond KAG, Geppert CM, Heinrich T. 2005. Becoming a good doctor: perceived need for ethics training focused on practical and professional development topics. Academic Psychiatry. 29: 301-309.

Robins LS, Braddock III CH, Fryer-Edwards KA. 2002. Using the American Board of Internal Medicine's "Elements of Professionalism" for undergraduate ethics education. Academic Medicine. 77: 523-531.

Rogers ME, Creed PA, Searle J. 2014. Emotional labour, training stress, burnout, and depressive symptoms in junior doctors. Journal of Vocational Education and Train. 66: 232-248.

Rosenbaum ME, Ferguson KJ, Lobas JG. 2004. Teaching medical students and residents skills for delivering bad news: a review of strategies. Academic Medicine. 79: 107-117. 
Schaufeli WB, Bakker AB, Van der Heijden FM, Prins JT. 2009. Workaholism, burnout and well-being among junior doctors: the mediating role of role conflict. Work and Stress. 23: 155-172.

Shibu PK, Subramonian S, Suresh M, Vindlacheruvu M, Cheeroth S, Myint PK. 2008. Junior doctors' awareness of terminology relating to key medico-legal and ethical principles: a questionnaire survey. Clinical Medicine. 8: 231-232.

Sokol DK. 2010. What to tell junior doctors about ethics. Br Med Journal. 340: c2489.

Sokol D, Doyal L, Doyal L. 2010. Ethics, law, and the junior doctor. Postgrad Med Journal. 86: $629-630$.

Tasker F, Newbery N, Burr B, Goddard AF. 2014. Survey of core medical trainees in the United Kingdom 2013-inconsistencies in training experience and competing with service demands. Clinical Medicine. 14: 149-156.

UK Foundation Programme Curriculum. (2016). [Accessed 5 February 2019] http://www.foundationprogramme.nhs.uk/curriculum/syllabus.html

Van Hamel C. Jenner LE. 2015. Prepared for practice? a national survey of UK foundation doctors and their supervisors. Med Teach. 37: 181-188.

Vivekananda-Schmidt P, Vernon B. 2014. FY1 doctors' ethicolegal challenges in their first year of clinical practice: an interview study. Journal of Med Ethics. 40: 277281.

Wakeling J, French F, Bagnall G, McHardy K. 2011. Is Foundation training producing competent doctors? What do Foundation trainees, educational supervisors and nurses in Scotland have to say? Scott Med Journal. 56: 87-93.

Wall D, Bolshaw A, Carolan J. 2006. From undergraduate medical education to preregistration house officer year: how prepared are students?. Med Teach, 28(5), 435439. 


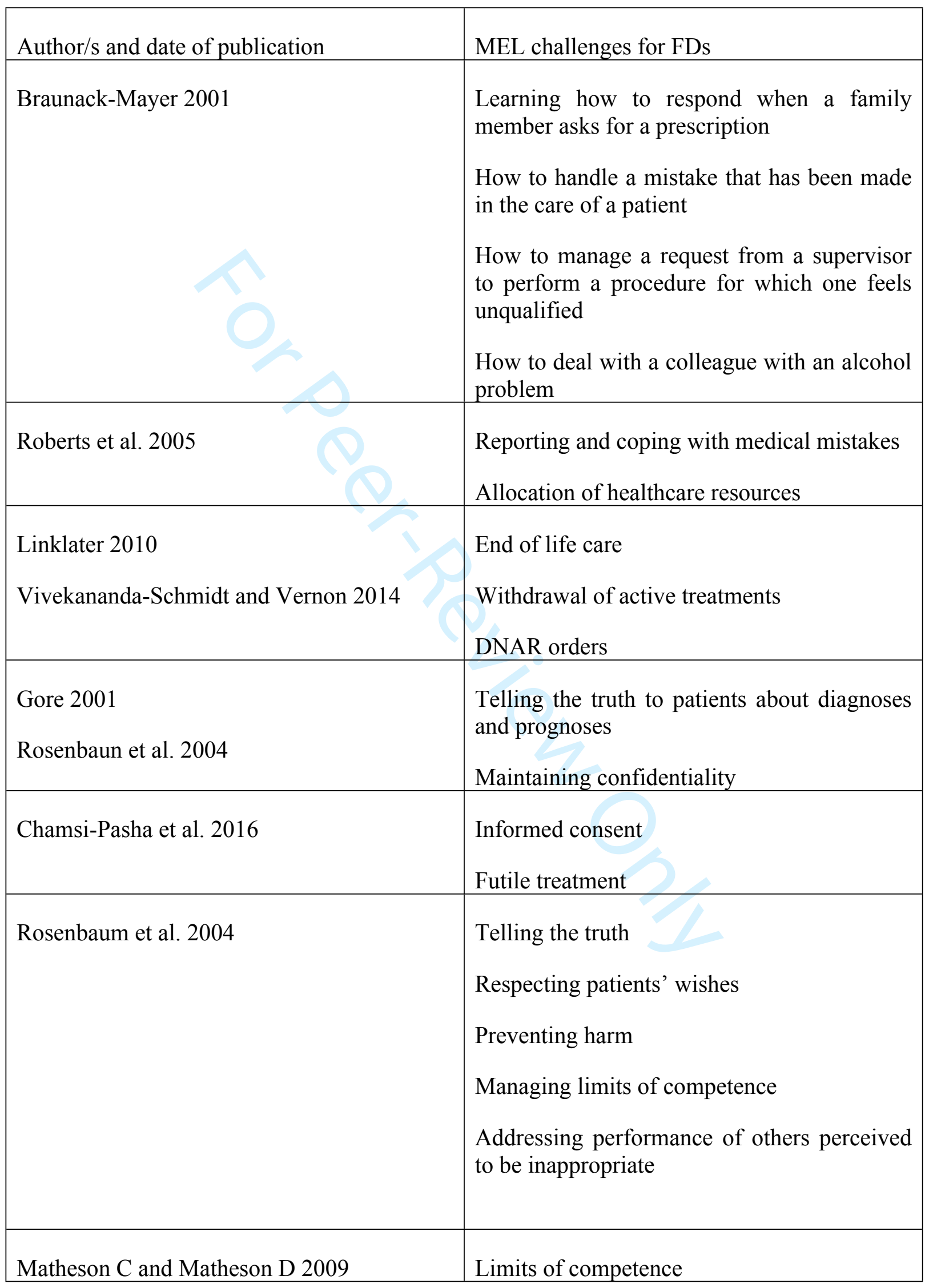




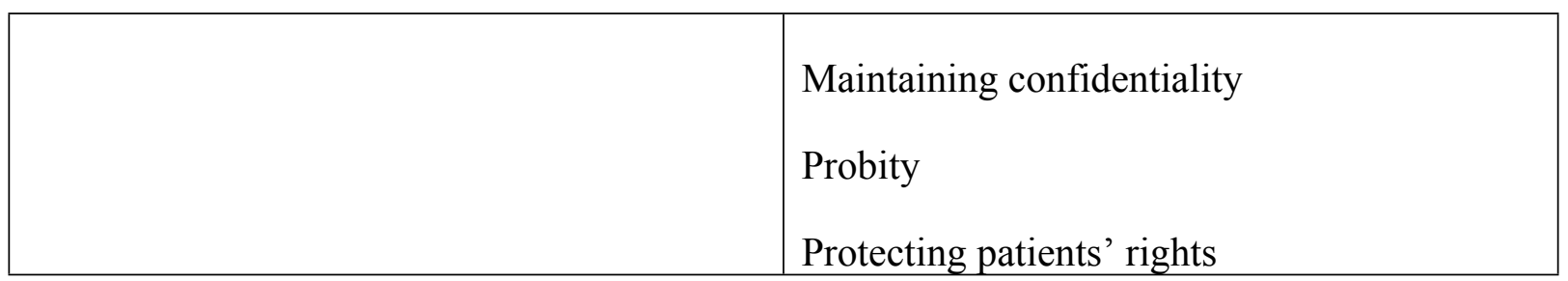

Table 1: A brief summary of the medical ethics and legal challenges that Foundation Doctors face based on literature review 


\begin{tabular}{|c|c|}
\hline Author/s and date of publication & MEL training topics for FDs \\
\hline Kirkham and Baker 2012 & $\begin{array}{l}\text { 'Professionalism' e.g. NICE guidelines } \\
\text { 'Medical law' e.g. safeguarding, MCA } \\
\text { 'Leadership' e.g. communication/breaking } \\
\text { bad news } \\
\text { 'Patient safety' e.g. prescribing errors, } \\
\text { system failures }\end{array}$ \\
\hline Sokol 2010 & $\begin{array}{l}\text { Consent } \\
\text { Confidentiality } \\
\text { End of life decisions capturing DNAR orders } \\
\text { Quality of life and the concept of futility } \\
\text { Meaning of best interests } \\
\text { Organisational ethics } \\
\text { Whistleblowing } \\
\text { Clinical negligence }\end{array}$ \\
\hline McDougall and Sokol 2008 & $\begin{array}{l}\text { Telling the truth } \\
\text { Respecting patients' autonomy } \\
\text { Preventing harm } \\
\text { Managing the limits of one's competence } \\
\text { Addressing the inappropriate behaviour of } \\
\text { others } \\
\text { Conflicts of interest } \\
\text { Setting interpersonal boundaries with patients } \\
\text { Impact of working conditions }\end{array}$ \\
\hline Levy and Coward 2010 & Consent \\
\hline
\end{tabular}

Table 2: Suggested content of medical ethics and legal training for Foundation Doctors 


\begin{tabular}{|c|c|c|c|}
\hline Variables & Values & Observations & Percentages \\
\hline \multirow[t]{7}{*}{ Age } & Under 20 & 1 & $0.21 \%$ \\
\hline & $20-24$ & 136 & $28.4 \%$ \\
\hline & $25-29$ & 292 & $60.96 \%$ \\
\hline & $30-34$ & 30 & $6.26 \%$ \\
\hline & $35-39$ & 10 & $2.09 \%$ \\
\hline & $40+$ & 6 & $1.25 \%$ \\
\hline & Prefer not to say & 4 & $0.83 \%$ \\
\hline \multirow[t]{3}{*}{ Gender } & Female & 308 & $64.3 \%$ \\
\hline & Male & 158 & $33 \%$ \\
\hline & Prefer not to say & 13 & $2.7 \%$ \\
\hline \multirow[t]{3}{*}{ Career Stage } & $\mathrm{F} 1$ & 218 & $45.5 \%$ \\
\hline & F2 & 254 & $53 \%$ \\
\hline & Prefer not to say & 7 & $1.5 \%$ \\
\hline \multirow[t]{5}{*}{ Medical School } & Non-UK & 38 & $7.93 \%$ \\
\hline & Wales & 23 & $4.8 \%$ \\
\hline & Scotland & 96 & $20.04 \%$ \\
\hline & Ireland & 2 & $0.42 \%$ \\
\hline & England & 320 & $66.81 \%$ \\
\hline \multirow[t]{3}{*}{ Deanery } & Wales & 29 & $6.05 \%$ \\
\hline & Scotland & 117 & $24.42 \%$ \\
\hline & England & 331 & $69.11 \%$ \\
\hline
\end{tabular}




\begin{tabular}{|l|l|l|l|}
\hline & Prefer not to say & 2 & $0.42 \%$ \\
\hline $\begin{array}{l}\text { Completed MSc Med } \\
\text { Ethics/Law }\end{array}$ & Yes & 6 & $1.25 \%$ \\
\hline & No & 471 & $98.3 \%$ \\
\hline & Prefer not to say & 2 & $0.45 \%$ \\
\hline
\end{tabular}

Table 3: Demographic profile of respondents 


\begin{tabular}{|l|l|l|}
\hline Topic & $\begin{array}{l}\text { Observations } \\
(\mathrm{n}=447)\end{array}$ & Percentages \\
\hline Confidentiality & 427 & $95.53 \%$ \\
\hline $\begin{array}{l}\text { Consent including how to Assess Capacity and } \\
\text { Proceed when an Individual Lacks Capacity }\end{array}$ & 404 & $90.38 \%$ \\
\hline Dignity and Patient-Centred Care & 388 & $86.8 \%$ \\
\hline Mental Health Act Sectioning & 384 & $85.91 \%$ \\
\hline Safeguarding of Children and Adults & 381 & $85.23 \%$ \\
\hline Ethical Theories and Principles & 373 & $83.45 \%$ \\
\hline $\begin{array}{l}\text { Being Open and Honest (Accountability, Patient } \\
\text { Complaints) }\end{array}$ & 370 & $82.77 \%$ \\
\hline End of Life & 369 & $82.55 \%$ \\
\hline DNACPR Decisions & 368 & $82.33 \%$ \\
\hline Use of Social Media & 347 & $77.63 \%$ \\
\hline
\end{tabular}

Table 4: Top ten topics taught at medical school (447 respondents answered this question) 


\begin{tabular}{|l|l|l|}
\hline Topic & $\begin{array}{l}\text { Observations } \\
(\mathrm{n}=447)\end{array}$ & Percentages \\
\hline DOLs & 185 & $41.39 \%$ \\
\hline Paediatric Ethics & 177 & $39.6 \%$ \\
\hline Decision Making in Emergency Medicine & 165 & $36.91 \%$ \\
\hline Self-Discharge Against Medical Advice & 164 & $36.69 \%$ \\
\hline Beginning of Life & 135 & $30.2 \%$ \\
\hline Resource Allocation & 125 & $27.96 \%$ \\
\hline Structure of the Legal System & 107 & $23.94 \%$ \\
\hline Sedation & 100 & $22.37 \%$ \\
\hline Providing Care in Detention Settings & 68 & $15.2 \%$ \\
\hline Being a Doctor in the Military & 25 & $5.6 \%$ \\
\hline
\end{tabular}

Table 5: Bottom ten topics taught at medical school 


\begin{tabular}{|c|c|c|}
\hline Topics & Observations $(n=285)$ & Percentages \\
\hline $\begin{array}{l}\text { Self-Discharge Against Medical } \\
\text { Advice }\end{array}$ & 50 & $17.54 \%$ \\
\hline Structure of the Legal System & 45 & $15.78 \%$ \\
\hline DOLs & 43 & $15.08 \%$ \\
\hline DNACPR Decisions & 35 & $12.28 \%$ \\
\hline Whistleblowing & 33 & $11.57 \%$ \\
\hline End of Life & 28 & $9.82 \%$ \\
\hline $\begin{array}{l}\text { Decision Making in Emergency } \\
\text { Medicine }\end{array}$ & 26 & $9.12 \%$ \\
\hline Sedating Patients & 24 & $8.42 \%$ \\
\hline $\begin{array}{l}\text { Withholding/Withdrawing } \\
\text { Treatment }\end{array}$ & 20 & $7.01 \%$ \\
\hline $\begin{array}{l}\text { Providing Care in Detention } \\
\text { Settings }\end{array}$ & 19 & $6.66 \%$ \\
\hline Human Rights & 19 & $6.66 \%$ \\
\hline Mental Health Act Sectioning & 18 & $6.31 \%$ \\
\hline $\begin{array}{l}\text { Consent including how to Assess } \\
\text { Capacity and Proceed when an } \\
\text { Individual Lacks Capacity }\end{array}$ & 17 & $5.96 \%$ \\
\hline Paediatric Ethics & 16 & $5.61 \%$ \\
\hline Resource Allocation & 15 & $5.26 \%$ \\
\hline Being a Doctor in the Military & 14 & $4.91 \%$ \\
\hline $\begin{array}{l}\text { Safeguarding of Children and } \\
\text { Adults }\end{array}$ & 11 & $3.85 \%$ \\
\hline Beginning of Life & 10 & $3.50 \%$ \\
\hline Medical Research & 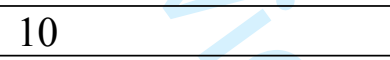 & $3.50 \%$ \\
\hline Global Health & 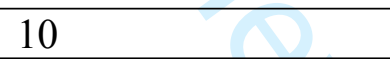 & $3.50 \%$ \\
\hline $\begin{array}{l}\text { Treating Patients with Suicidal } \\
\text { Intent }\end{array}$ & 9 & $3.15 \%$ \\
\hline Confidentiality & 4 & $1.40 \%$ \\
\hline Use of Social Media & 4 & $1.40 \%$ \\
\hline Ethical Theories and Principles & 4 & $1.40 \%$ \\
\hline Statutory Legal Duty of Candour & 3 & $1.05 \%$ \\
\hline $\begin{array}{lll}\text { Being Open and } & \text { Honest } \\
\text { (Accountability, } & & \text { Patient } \\
\text { Complaints) } & & \\
\end{array}$ & 3 & $1.05 \%$ \\
\hline Genetic Testing and Screenings & 1 & $0.35 \%$ \\
\hline Dignity and Patient-Centred Care & 0 & 0 \\
\hline
\end{tabular}

Table 6: Medical ethics and legal topics respondents would have liked to have received training on during medical school (285 respondents answered this question) 


\begin{tabular}{|c|c|c|c|}
\hline Topic & $\begin{array}{l}\text { Total } \\
(n=427)^{*}\end{array}$ & FY1 (n=199) & FY2 $(n=224)$ \\
\hline Self-Discharge Against Medical Advice & $302(70.7 \%)$ & $137(68.8 \%)$ & $162(72.3 \%)$ \\
\hline Sedating Patients & $299(70.0 \%)$ & $145(72.9 \%)$ & $152(67.9 \%)$ \\
\hline Decision Making in Emergency Medicine & $286(67.0 \%)$ & $133(66.8 \%)$ & $150(67.0 \%)$ \\
\hline Withholding/Withdrawing Treatment & $282(66.0 \%)$ & $127(63.8 \%)$ & $153(68.3 \%)$ \\
\hline DNACPR Decisions & $271(63.5 \%)$ & $123(61.8 \%)$ & $146(65.2 \%)$ \\
\hline Treating Patients with Suicidal Intent & $251(58.8 \%)$ & $111(55.8 \%)$ & $139(62.1 \%)$ \\
\hline Whistleblowing & $241(56.4 \%)$ & $102(51.3 \%)$ & $137(61.2 \%)$ \\
\hline Mental Health Act Sectioning & $236(55.3 \%)$ & $107(53.8 \%)$ & $127(56.7 \%)$ \\
\hline DOLs & $230(53.9 \%)$ & $111(55.8 \%)$ & $116(51.8 \%)$ \\
\hline End of Life & $227(53.2 \%)$ & $102(51.3 \%)$ & $124(55.4 \%)$ \\
\hline $\begin{array}{l}\text { Consent including how to Assess Capacity and } \\
\text { Proceed when an Individual Lacks Capacity }\end{array}$ & $215(50.4 \%)$ & $105(52.8 \%)$ & $108(48.2 \%)$ \\
\hline Structure of the Legal System & $206(48.2 \%)$ & $122(61.3 \%)$ & $81(36.2 \%)$ \\
\hline Safeguarding of Children and Adults & $185(43.3 \%)$ & $85(42.7 \%)$ & $98(43.8 \%)$ \\
\hline Paediatric Ethics & $179(41.9 \%)$ & $76(38.2 \%)$ & $101(45.1 \%)$ \\
\hline Resource Allocation & $160(37.5 \%)$ & $66(33.2 \%)$ & $91(40.6 \%)$ \\
\hline Providing Care in Detention Settings & $148(34.7 \%)$ & $65(32.7 \%)$ & $82(36.6 \%)$ \\
\hline Statutory Legal Duty of Candour & $144(33.7 \%)$ & $68(34.2 \%)$ & $75(33.5 \%)$ \\
\hline $\begin{array}{l}\text { Being Open and Honest (Accountability, Patient } \\
\text { Complaints) }\end{array}$ & $142(33.3 \%)$ & $61(30.7 \%)$ & $80(35.7 \%)$ \\
\hline Beginning of Life & $141(33.0 \%)$ & $55(27.6 \%)$ & $84(37.5 \%)$ \\
\hline Confidentiality & $129(30.2 \%)$ & $59(29.6 \%)$ & $69(30.8 \%)$ \\
\hline Human Rights & $118(27.6 \%)$ & $53(26.6 \%)$ & $64(28.6 \%)$ \\
\hline Medical Research & $115(26.9 \%)$ & $53(26.6 \%)$ & $61(27.2 \%)$ \\
\hline Genetic Testing and Screening & $112(26.2 \%)$ & $53(26.6 \%)$ & $57(25.4 \%)$ \\
\hline Dignity and Patient-Centred Care & $102(23.9 \%)$ & $50(25.1 \%)$ & $51(22.8 \%)$ \\
\hline Global Health & $95(22.3 \%)$ & $43(21.6 \%)$ & $50(22.3 \%)$ \\
\hline Use of Social Media & $86(20.1 \%)$ & $36(18.1 \%)$ & $49(21.9 \%)$ \\
\hline Being a Doctor in the Military & $73(17.1 \%)$ & $35(17.6 \%)$ & $36(16.1 \%)$ \\
\hline
\end{tabular}

Table 7: Additional training respondents would wish to receive during Foundation Programme

*NB 4 respondents to this question did not specify F1 or F2 and therefore their responses are included in the total only 


\begin{tabular}{|l|l|l|}
\hline Topic & $\begin{array}{l}\text { Observations } \\
(\mathrm{n}=426)\end{array}$ & Percentages \\
\hline Case Studies & 275 & $64.55 \%$ \\
\hline Seminars & 250 & $58.69 \%$ \\
\hline Workshops & 218 & $51.17 \%$ \\
\hline Lectures & 179 & $42.02 \%$ \\
\hline Simulation & 162 & $38.03 \%$ \\
\hline Group Work & 150 & $35.21 \%$ \\
\hline Interprofessional Learning & 74 & $17.37 \%$ \\
\hline Other & 13 & $3.05 \%$ \\
\hline
\end{tabular}

Table 8: Respondents' preferences for how additional training during Foundation Programme could be delivered (426 FY doctors answered this question) 